\title{
The Influence of Electrolytic Concentration on the Electrochemical Deposition of Calcium Phosphate Coating on a Direct Laser Metal Forming Surface
}

\author{
Qianyue Sun, ${ }^{1,2}$ Yuhui Yang, ${ }^{3}$ Wenjing Luo, ${ }^{1}$ Jinghui Zhao, ${ }^{1}$ and Yanmin Zhou' \\ ${ }^{1}$ Department of Dental Implantology, School and Hospital of Stomatology, Jilin University, Changchun, Jilin Province 130021, China \\ ${ }^{2}$ Key Laboratory of Oral Medicine, Guangzhou Institute of Oral Disease, Stomatology Hospital of Guangzhou Medical University, \\ Guangzhou 510140, China \\ ${ }^{3}$ Department of Orthopaedics, China-Japan Union Hospital of Jilin University, Changchun, Jilin Province 130033, China
}

Correspondence should be addressed to Jinghui Zhao; zhaojh_1986@126.com and Yanmin Zhou; zhouym62@126.com

Received 11 November 2016; Revised 31 December 2016; Accepted 10 January 2017; Published 29 January 2017

Academic Editor: Jiu-Ju Feng

Copyright ( 2017 Qianyue Sun et al. This is an open access article distributed under the Creative Commons Attribution License, which permits unrestricted use, distribution, and reproduction in any medium, provided the original work is properly cited.

\begin{abstract}
A calcium phosphate $(\mathrm{CaP})$ coating on titanium surface enhances its biocompatibility, thus facilitating osteoconduction and osteoinduction with the inorganic phase of the human bone. Electrochemical deposition has been suggested as an effective means of fabricating $\mathrm{CaP}$ coatings on porous surface. The purpose of this study was to develop CaP coatings on a direct laser metal forming implant using electrochemical deposition and to investigate the effect of electrolytic concentration on the coating's morphology and structure by X-ray diffraction, scanning electron microscopy, water contact angle analysis, and Fourier transform infrared spectroscopy. In group $10^{-2}$, coatings were rich in dicalcium phosphate, characterized to be thick, layered, and disordered plates. In contrast, in groups $10^{-3}$ and $10^{-4}$, the relatively thin and well-ordered coatings predominantly consisted of granular hydroxyapatite. Further, the hydrophilicity and cell affinity were improved as electrolytic concentration increased. In particular, the cells cultured in group $10^{-3}$ appeared to have spindle morphology with thick pseudopodia on CaP coatings; these spindles and pseudopodia strongly adhered to the rough and porous surface. By analyzing and evaluating the surface properties, we provided further knowledge on the electrolytic concentration effect, which will be critical for improving CaP coated Ti implants in the future.
\end{abstract}

\section{Introduction}

Many dental and orthopedic implants are manufactured from titanium ( $\mathrm{Ti})$ as it has excellent mechanical properties, such as corrosion resistance and biocompatibility [1]. However, conventional Ti implants also have some limitations. Mismatched elastic modulus between the implant and native bone leads to stress shielding and implant failure [2]. Since pure Ti implant contains an inert metal and lacks osteoinduction, it mechanically interlocks with the bone surface without forming a chemical bond [3]. Therefore, many researchers have attempted to develop surface treatment methods that improve the efficacy and bone-bonding ability of Ti dental implants.

Rapid prototyping (RP) technologies can directly fabricate individualized products with defined morphology and structure on the basis of virtual three-dimensional (3D) data. According to a computer assisted design (CAD) file, direct laser metal forming (DLMF) has been used to produce laser-sintered titanium implants, which are usually known as TixOs $^{\circledR}$ implants (Leader-Novaxa, Milan, Italy) [4-6]. The surface of this implant is characterized by a 3D network of interconnected pores that can significantly facilitate cell growth and bone deposition. The surface morphology and elastic modulus of these implants are also designed to resemble the structure and morphology of porous alveolar bone [7]. Moreover, the core of such implants retains the excellent mechanical properties of Ti. Hence, these implants have high overall strength and rigidity.

Many research studies [8] have given promising results showing that depositing calcium phosphate $(\mathrm{CaP})$ coating on the surface of Ti implants can improve the bioinert surface 
TABLE 1: Experimental groups of different electrolytic concentrations.

\begin{tabular}{lcccc}
\hline Electrolyte & Group $10^{-2}$ & Group $10^{-3}$ & Group $10^{-4}$ & Control group \\
\hline $\mathrm{Ca}\left(\mathrm{NO}_{3}\right)_{2} \cdot 4 \mathrm{H}_{2} \mathrm{O}$ & $6.0 \times 10^{-2} \mathrm{~mol}$ & $6.0 \times 10^{-3} \mathrm{~mol}$ & $6.0 \times 10^{-4} \mathrm{~mol}$ & \\
$\left(\mathrm{NH}_{4}\right) \mathrm{H}_{2} \mathrm{PO}_{4}$ & $3.6 \times 10^{-2} \mathrm{~mol}$ & $3.6 \times 10^{-3} \mathrm{~mol}$ & $3.6 \times 10^{-4} \mathrm{~mol}$ & Ti implant \\
$\mathrm{NaNO}_{3}$ & - & $0.1 \mathrm{~mol}$ & $0.1 \mathrm{~mol}$ & \\
\hline
\end{tabular}

of titanium alloys. Moreover, the coating's structural and chemical properties are similar to those of human bone tissue [9-12]. CaP coating, as a main compound in the inorganic bone matrix, significantly improves the biocompatibility, osteoconduction, and osteoinduction of Ti implants, as shown in the study by de Jonge et al. [13]. Furthermore, the release of chemical elements ( $\mathrm{Ca}$ and $\mathrm{P}$ ) from the coating can be cleared through a series of metabolic pathways [14]. After fixing the $\mathrm{Ti}$ implant, the $\mathrm{CaP}$ coating can form chemical bonds with adjacent bone tissue [15], thus forming a scaffold to facilitate the formation of new bone [16]. The CaP coating is remodeled into new bone as it eventually undergoes degradation; this new bone absorbs the less stable CaP phases of the coating. In addition, many researchers have claimed that the highly crystalline form of pure hydroxyapatite (HAP) is an effective bioactive coating on Ti surfaces [17].

Different methods have been developed for coating CaP layers onto implant surfaces, such as plasma spray [18], solgel [19], biomimetic [20], chemical vapor deposition [21], ion implantation [22], and electrochemical deposition [23]. Electrochemical deposition, a liquid-based process, has been suggested as an effective means of fabricating $\mathrm{CaP}$ coatings on intricate geometry substrates [24]. By using a lower working temperature, changes in the chemical composition and crystal structure of the substrate (normally caused by conventional sintering processes) can be avoided [23]. Meanwhile, the chemical composition, physical phases, and microstructure of substrates subjected to electrochemical deposition are controlled by parameters associated with the process of deposition, such as deposition temperature, voltage, current density, and electrolytic concentration [25]. Even electrochemical deposition was demonstrated to promptly functionalize $3 \mathrm{D}$ porous $\mathrm{Ti}$ structures with $\mathrm{CaP}$ layers and offer higher controllability and reproducibility on the surface coating $[24,26]$. Very few studies have reported the effect of electrolytic concentration on the structure and morphology of $\mathrm{CaP}$ coatings.

In this study, we determined how different electrolytic concentrations affected the structure and morphology of $\mathrm{CaP}$ coatings on porous Ti implant surfaces. We also determined the predominant composition and cellular adhesion of $\mathrm{CaP}$ coatings produced by electrochemical deposition on the surface of DLMF implants.

\section{Materials and Methods}

2.1. Preparation of Specimens. In this experimental study, cylindrical TixOs plates ( $2 \mathrm{~mm}$ thick and $10 \mathrm{~mm}$ in diameter) were obtained from Leader Italia Srl (Cinisello Balsamo,
Italy). Using a DLMF technique, the plates were manufactured from an alloy powder (Ti-6Al-4V), with a particle size of $25-45 \mu \mathrm{m}$ as the base material.

\subsection{Electrochemical Deposition of CaP Coating}

2.2.1. Experimental Groups. Based on the concentration of $\mathrm{Ca}\left(\mathrm{NO}_{3}\right)_{2}$ in the aqueous solution, we classified different electrolytic concentrations into three concentration-level groups: group $10^{-2}$, group $10^{-3}$, and group $10^{-4}$ (Table 1). The ratio of $\mathrm{Ca} / \mathrm{P}$ in electrolyte was kept constant at 1.67 to ensure the stoichiometric levels were consistent with HAP, as reported previously $[27,28]$.

2.2.2. Experimental Procedure. In this experiment, electrochemical deposition was used to form CaP coatings on the surface of Ti plates. We initially prepared three solutions of different electrolytic concentrations. Depending on the different concentrations of $\left(\mathrm{NH}_{4}\right) \mathrm{H}_{2} \mathrm{PO}_{4}$ and $\mathrm{Ca}\left(\mathrm{NO}_{3}\right)_{2} \cdot 4 \mathrm{H}_{2} \mathrm{O}$ in distilled water, we defined three experimental groups: group $10^{-2}$, group $10^{-3}$, and group $10^{-4}$. The bare Ti implants were used as the control group. We dissolved $0.1 \mathrm{~mol}$ of $\mathrm{NaNO}_{3}$ in the electrolytic solutions of groups $10^{-3}$ and $10^{-4}$ to increase their ionic conductivity. The acidity of the electrolytic solutions was maintained at $\mathrm{pH} 6$ using ammonia water. The electrochemical deposition was conducted for 40 minutes at a constant potential of $-2.5 \mathrm{~V}$. During this process, the temperature was maintained at $70^{\circ} \mathrm{C}$. The plate specimens and a platinum electrode were used as the cathode and anode, respectively. The distance between the electrodes was maintained at $10 \mathrm{~mm}$. The potentials were recorded during the coating process. Finally, the deposits were gently rinsed with distilled water and dried overnight at room temperature.

2.3. Microstructure and Structural Characterization. The microstructure of deposits was analyzed by scanning electron microscopy (SEM) (XL30ESEM-FEG; FEL, Amstelveen, Netherlands). The crystal phase and constituents of calcium phosphate coating were investigated by X-ray diffraction (XRD) (D8 Advance; Bruker, Karlsruhe, Germany) and Fourier transform infrared spectroscopy (FTIR) (D8 Advance; Bruker, Karlsruhe, Germany), respectively. Further, the hydrophilic property of implants was characterized by measuring the static water contact angles at room temperature.

2.4. Cell Culture Experiment. According to the experimental design, the human osteoblast-like MG-63 cell line was cultured in Dulbecco's Modified Eagle Medium (DMEM), 


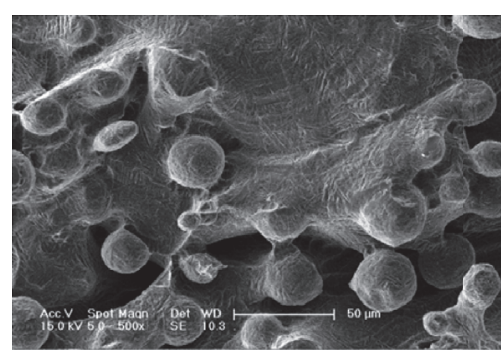

(a1)

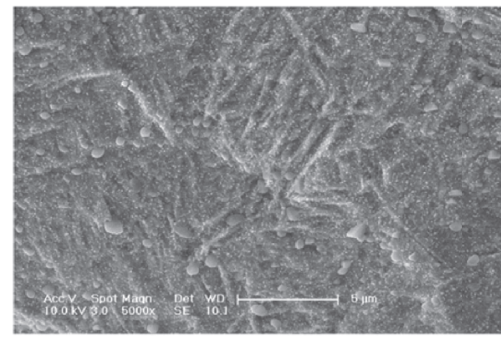

(b1)

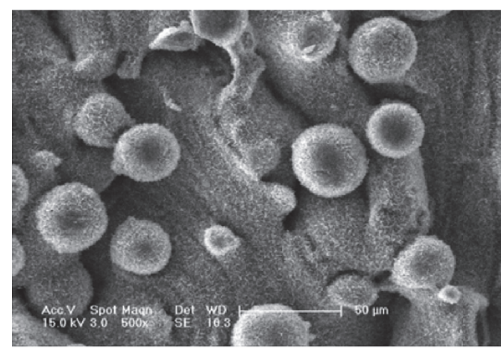

$(\mathrm{c} 1)$

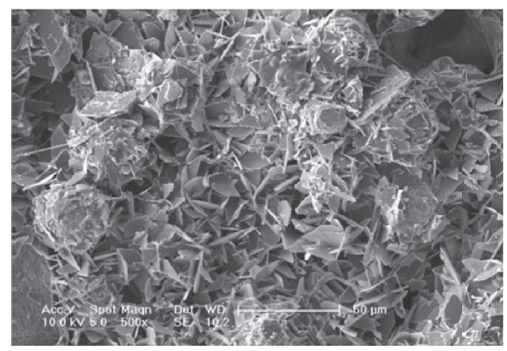

$(\mathrm{d} 1)$

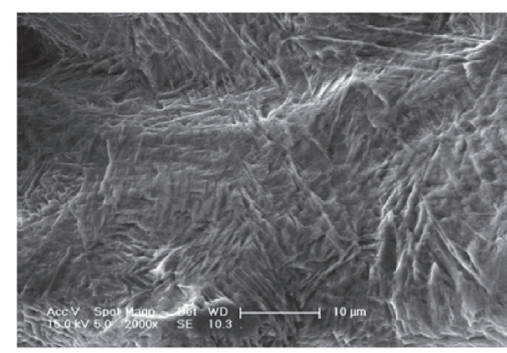

(a2)

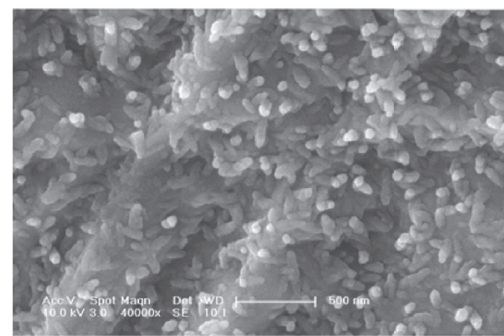

(b2)

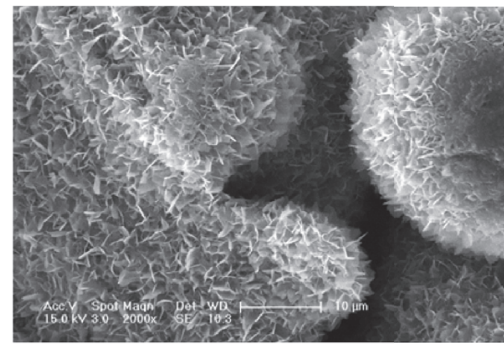

(c2)

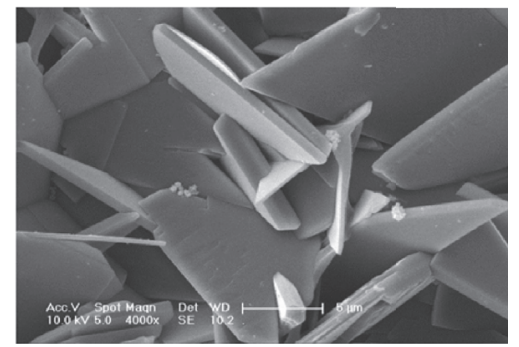

(d2)

FIGURE 1: SEM micrographs of the bare Ti implant (al) and of the CaP coating obtained using different electrolytic concentrations: group $10^{-4}$ (b1); group $10^{-3}(\mathrm{cl})$; and group $10^{-2}(\mathrm{~d} 1)$. The photographs (a2-d2) were the corresponding magnified images.

which was supplemented with $10 \%$ fetal calf serum and $1 \%$ penicillin. This cell culture was incubated at $37^{\circ} \mathrm{C}$ in a humidified atmosphere containing $5 \% \mathrm{CO}_{2}$. The cells were seeded and cultured on the surface of specimens obtained from the three different groups for a time-period of 1,3 , and 7 days; the cell density was maintained at $5 \times 10^{4}$ cells $/ \mathrm{cm}^{2}$. After gently rinsing with phosphate-buffered saline (PBS), we fixed these specimens for 2 hours in $2.5 \%$ glutaraldehyde at $4^{\circ} \mathrm{C}$. After fixing these specimens, we dehydrated them using a series of ethanol solutions of increasing concentrations: 30 , 50, 70, 80, 90, 95, and 100\%. These ethanol solutions were subsequently sprayed on the specimens. Finally, a SEM was used to analyze the morphology of cells cultured on these specimens.

\section{Results}

3.1. Morphological Analysis. The DLMF implant surface (Figure 1(a1)) was covered with spherical particles with a diameter of 30 to $50 \mu \mathrm{m}$. The titanium spherical particles had a porous structure; the diameter of these pores varied between 200 and $300 \mu \mathrm{m}$ (Figure 1(a2)). In group $10^{-4}$ (Figure 1(b1)), the thin $\mathrm{CaP}$ coating had rod-like morphology; these tiny rods were $200 \mathrm{~nm}$ long and their diameters were $60-80 \mathrm{~nm}$. These tiny rods randomly covered the thin surface of the $\mathrm{CaP}$ coating. Under large magnification (Figure 1(b2)), we found that the surface of the rods was smooth. The coating exhibited layers of crystal growth, in which larger tabular crystals were found to be superposed on thin layers of crystals. This indicated that the coating was formed by a process involving 
classical nucleation and growth. The surface of the specimen of group $10^{-3}$ (Figure 1(c1)) had a porous, well-ordered lattice, which was covered by structural laminas of $\mathrm{CaP}$ coatings, having cauliflower morphology. In a highly magnified image (Figure 1(c2)), we found that the coating was composed of crystal structures, having a thickness of $30-50 \mathrm{~nm}$ and a length of $1-2 \mu \mathrm{m}$. The specimen of group $10^{-2}$ (Figure 1(d1)) had a very thick coating that was composed of disorderly deposited plates, in which the micropores were completely covered with $\mathrm{CaP}$ deposits. The highly magnified micrograph (Figure 1(d2)) showed that thin CaP crystals appeared as flat interwoven plates. The thickness and length of these crystals were $600 \mathrm{~nm}$ and $10 \mu \mathrm{m}$, respectively.

3.2. Deposition Current Density. A potentiostatic method was used for carrying out the deposition of $\mathrm{CaP}$ coating. Figure 2 illustrates the plot of electric current against the applied potential. The deposition of $\mathrm{CaP}$ was carried out at a constant potential. As the concentration of the electrolyte increased at the electrode surface, the electric current also showed an upward trend. A higher electric current accelerated the deposition of the electrolyte at the cathode. Although the rate of deposition improved, a higher electric current also generated excessive $\mathrm{OH}^{-}$ions [29], leading to the formation of a flocculent precipitate as $\mathrm{CaP}$ was deposited away from the cathode. The CaP coating generated under these conditions appeared to be loose and disordered, thus causing lower adhesion strength between the coating and the surface.

\subsection{Composition and Structural Analysis}

3.3.1. X-Ray Diffraction (XRD) Analysis. Figure 3 shows the XRD patterns of various specimens. Most clusters have components located in the $2 \theta$ region between $33^{\circ}$ and $41^{\circ}$, which illustrated titanium oxides were presenting in the titanium interlayer [30]. After comparing these XRD patterns with the standard XRD curve of HAP (JCPDS 090432), we proposed that the diffraction peaks of groups $10^{-3}$ and $10^{-4}$ represented the HAP phase. The diffraction patterns of groups $10^{-3}$ and $10^{-4}$ showed peaks with the following $2 \theta$ values: $25.95^{\circ}$ (002), $31.96^{\circ}$ (211), and $49.52^{\circ}$ (213). Therefore, we inferred from the graph that the coatings of these two groups were predominantly composed of HAP. Moreover, in groups $10^{-3}$ and $10^{-4}$, the thickness of the coating and the intensity of diffraction peaks increased when we increased the electrolytic concentration. In group $10^{-2}$, the electrolytic concentration predominantly produced a highly crystalline phase of dibasic calcium phosphate dihydrate (DCPD; $\mathrm{CaHPO}_{4} \cdot 2 \mathrm{H}_{2} \mathrm{O}$ ).

3.3.2. Fourier Transform Infrared (FITR) Analysis. In the infrared spectra of $\mathrm{CaP}$ compounds, the characteristic peaks associated with the $\mathrm{P}-\mathrm{O}$ stretching vibrations appeared in the wavelength range 1200 to $900 \mathrm{~cm}^{-1}$, while the bands associated with the O-P-O bending vibrations appeared between 650 and $400 \mathrm{~cm}^{-1}$.

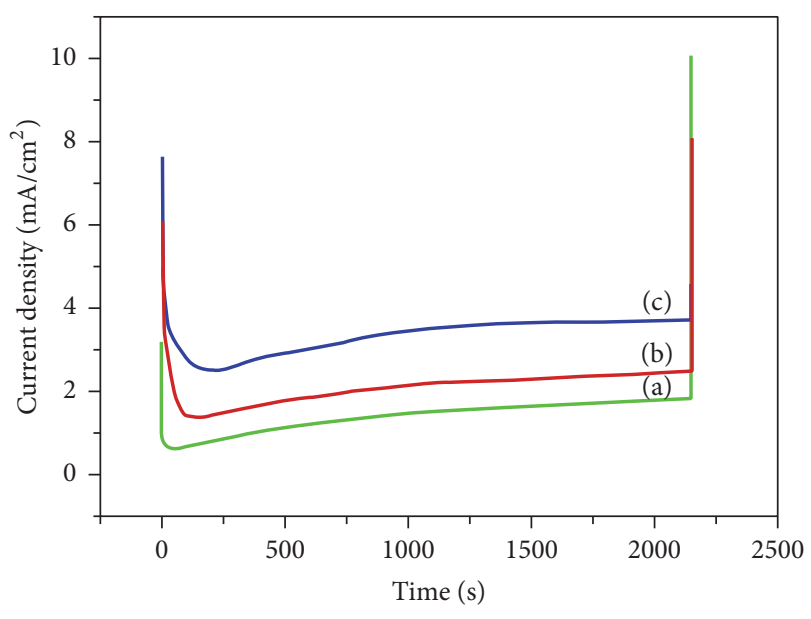

FIGURE 2: Current density during the electrochemical deposition of $\mathrm{CaP}$ coating using different electrolytic concentrations: group $10^{-4}$ (a), group $10^{-3}(\mathrm{~b})$, and group $10^{-2}(\mathrm{c})$.

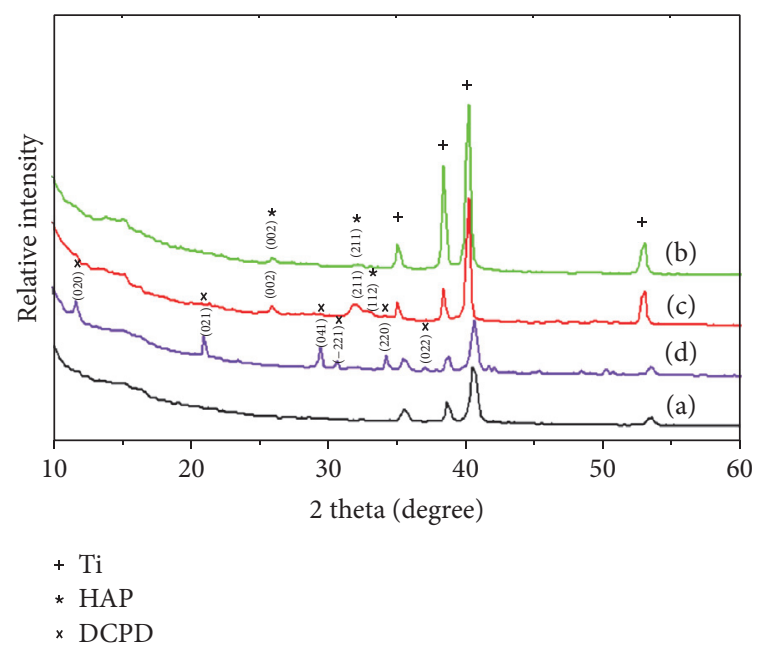

FIGURE 3: XRD pattern of the bare Ti implant specimen (a) and of the specimens coated with $\mathrm{CaP}$ at different electrolytic concentrations: group $10^{-4}(\mathrm{~b})$; group $10^{-3}(\mathrm{c})$; and group $10^{-2}(\mathrm{~d})$.

As shown in Figure 4, the FTIR spectra of $\mathrm{CaP}$ coatings were obtained using different concentrations of the electrolyte. The asymmetric stretching vibration peaks of $\mathrm{PO}_{4}{ }^{3-}$ ion appeared in the wavelength range $1010-1025 \mathrm{~cm}^{-1}$; these peaks were detected in the FTIR spectra of groups $10^{-3}$ and $10^{-4}$. The peak intensity of the group $10^{-3}$ was significantly higher than that of group $10^{-4}$, indicating that the group $10^{-3}$ had more $\mathrm{PO}_{4}{ }^{3-}$ ions and a thicker coating than group $10^{-4}$.

These findings revealed consistent conclusions regarding the XRD patterns and the SEM morphological analysis. The number of peaks detected in the group $10^{-2}$ was higher than that in the other groups, indicating that the coating of group $10^{-2}$ contained different functional groups. The characteristic peaks of group $10^{-2}$ were located at $1047 \mathrm{~cm}^{-1}, 1117 \mathrm{~cm}^{-1}$, and $1198 \mathrm{~cm}^{-1}$; these peaks were attributed to the asymmetric stretching vibrations of the phosphate groups [31]. 


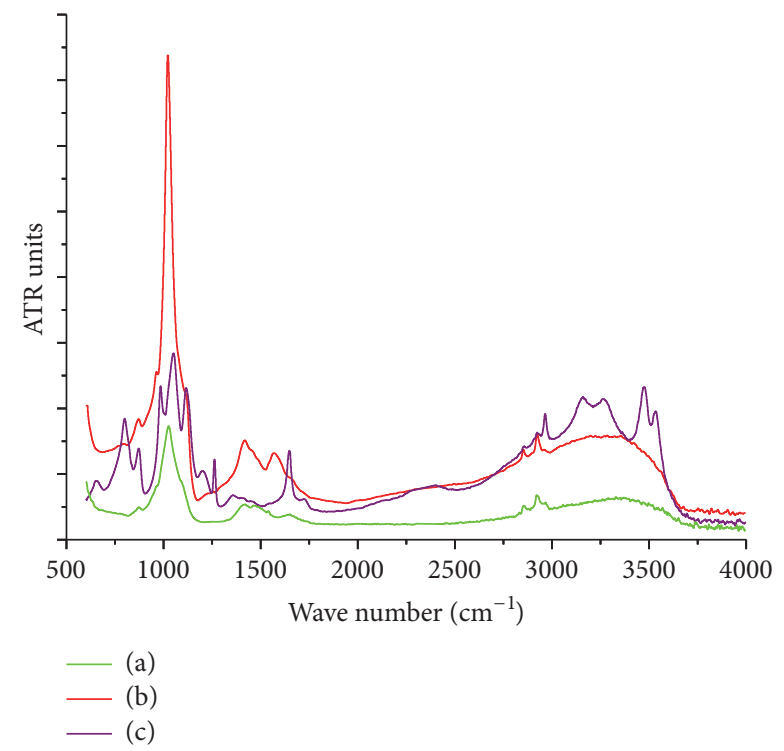

FIGURE 4: FTIR spectra of CaP coating at different electrolytic concentrations: group $10^{-4}$ (a), group $10^{-3}(\mathrm{~b})$, and group $10^{-2}(\mathrm{c})$.

The absorption band that appeared in the $2964-3570 \mathrm{~cm}^{-1}$ region was attributed to the $\mathrm{O}-\mathrm{H}$ stretching vibrations. The absorption peak near $1647 \mathrm{~cm}^{-1}$ was attributed to the bending vibration of crystalline water, indicating the presence of water in the coating. However, in the infrared spectra of groups $10^{-3}$ and $10^{-4}$, the absorption bands of water molecules were absent, indicating that these two compounds were anhydrous. Thus, the FTIR spectra of group $10^{-2}$ clearly represented the characteristic spectra of DCPD. Likewise, the absorption peaks of $\mathrm{CO}_{3}{ }^{2-}$ were detected at $1358 \mathrm{~cm}^{-1}, 870 \mathrm{~cm}^{-1}$, and $650 \mathrm{~cm}^{-1}$.

3.3.3. Hydrophilic Analysis. The wettability of the scaffolds was examined by static water contact angles analysis (Figure 5). The contact angle in control group was $122^{\circ}$, which implied the Ti implant surface appeared to be hydrophobic. The surface contact angles were $104^{\circ}, 76^{\circ}$, and $17^{\circ}$ for the groups $10^{-4}, 10^{-3}$, and $10^{-2}$, respectively. The contact angles in groups $10^{-2}$ and $10^{-3}$ were less than $90^{\circ}$, indicating these surfaces were hydrophilic. There were statistically significant differences among the four groups $(P<0.05)$.

3.4. Preliminary Evaluation of Biological Properties. We determined the morphology of MG63 cell line cultured on the pure Ti and coated DLMF implants. The SEM micrographs indicated that the morphologies of cultured MG63 cells appeared to be significantly different (Figure 6). On the pure Ti implant surface, the MG63 cells presented a round cell body and a flat cytoplasm with few pseudopodia, indicating that the attachment and spreading of cells on this surface were difficult due to the hydrophobic nature. In group $10^{-4}$, the adhered cells stretched better on the CaP coated surface with a relatively ellipse cytoplasm. In contrast, the cells in groups $10^{-3}$ and $10^{-2}$ spread better as they had an exuberant central area and several spindle projections on the $\mathrm{CaP}$ coated surfaces. Under high magnification (c1), we observed abundant cytoplasmic extensions, microfilaments, and thick pseudopodia that strongly adhered to the rough and porous surface in group $10^{-3}$.

\section{Discussion}

The electrochemical deposition is conducted by dissolving phosphate salts and calcium salts in deionized water. In this process, the electrolyte constantly produces $\mathrm{OH}^{-}$ions and $\mathrm{H}_{2}$ gas near the cathode. The ions released from the supersaturated solution of calcium phosphate accumulate on the surface of the specimens to produce a CaP coating [32].

Previous studies have reported that when $\mathrm{CaP}$ coating is produced by electrochemical deposition, the coating usually contains calcium phosphate dihydrate (DCPD), octacalcium phosphate (OCP), and HAP in higher proportions. A small amount of tricalcium phosphate (TCP) may also present in this coating. In this case, DCPD has the morphology of flat crystal wafers [33], while HAP has the morphology of thin needles. Further, electrolytic solutions containing more than $1 \mathrm{mM}$ of $\mathrm{Ca}^{2+}$ ions are considered high concentration solutions, while those containing less than $1 \mathrm{mM}$ of $\mathrm{Ca}^{2+}$ ions are considered low concentration solutions [34]. The concentration of ions can influence the crystallization process both dynamically and thermodynamically. According to a previous study [35], using electrolytic solutions of high concentrations, we obtained a deposition of DCPD and OCP with loose and irregular morphology. The deposition then transforms into HAP by conducting a postprocessing heat treatment. In contrast, using electrolytic solutions of low concentrations, we directly obtained a deposition of pure HAP, having uniform, compact, and controllable crystalline morphology. In this case, the XRD patterns showed that the diffraction peaks of group $10^{-2}$ were different from those of groups $10^{-3}$ and $10^{-4}$. Compared with the standard HAP pattern, the coating in the group $10^{-2}$ was predominantly DCPD. DCPD crystals are monoclinic [36], considered as the precursors of HAP [37]; they may transform into HAP by a postprocessing heat treatment. However, DCPD has a less stable structure than HAP due to its lower crystallinity [38]. Moreover, DCPD undergoes faster degradation, leading to premature loss of integrity in the coating and eventual implant failure.

Some researchers have reported that ceramic coatings bond with natural bone through a bone-like apatite layer between implant surface and the host bone [39]. FTIR is used to analyze the different functional groups existing in this coating. The bonds have been attributed to the peaks that appear in the FTIR spectra [40]. FTIR spectra showed that the absorption peaks of $\mathrm{CO}_{3}{ }^{2-}$ appeared around the following wavelengths: 1500,1420 , and $870 \mathrm{~cm}^{-1}$. Therefore, we inferred that, during the deposition, $\mathrm{CO}_{3}{ }^{2-}$ entered the HAP lattice and formed a carbonated hydroxyapatite, which is known as "bone-like apatite." Scientists consider the presence of $\mathrm{CO}_{3}{ }^{2-}$ leads to the formation of carbonated hydroxyapatite, which 


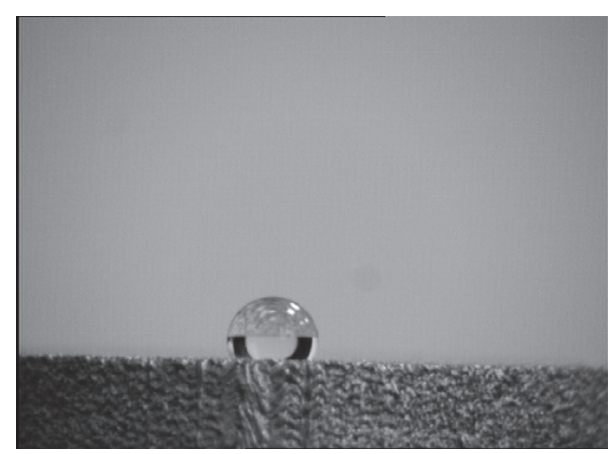

(a)

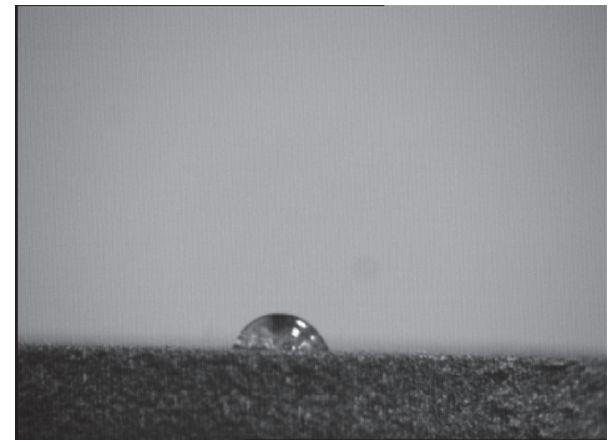

(c)

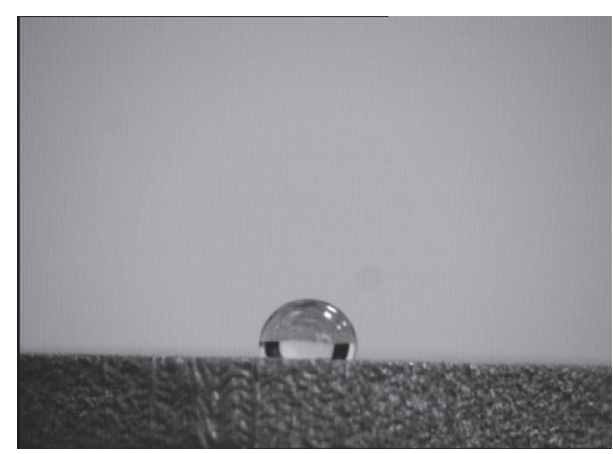

(b)

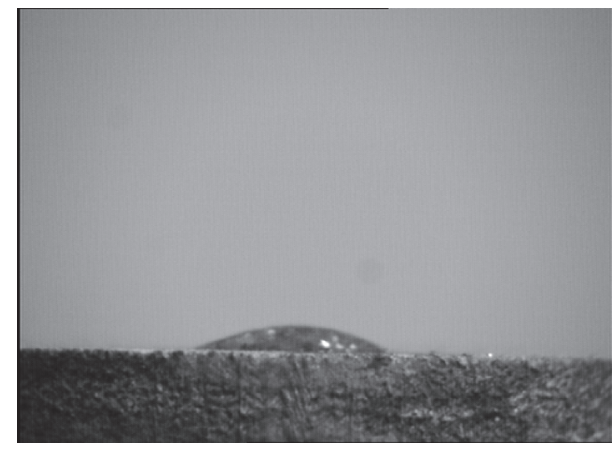

(d)

Figure 5: Contact angle of various study groups: control group (a), group $10^{-4}(\mathrm{~b})$, group $10^{-3}$ (c), and group $10^{-2}(\mathrm{~d})$.
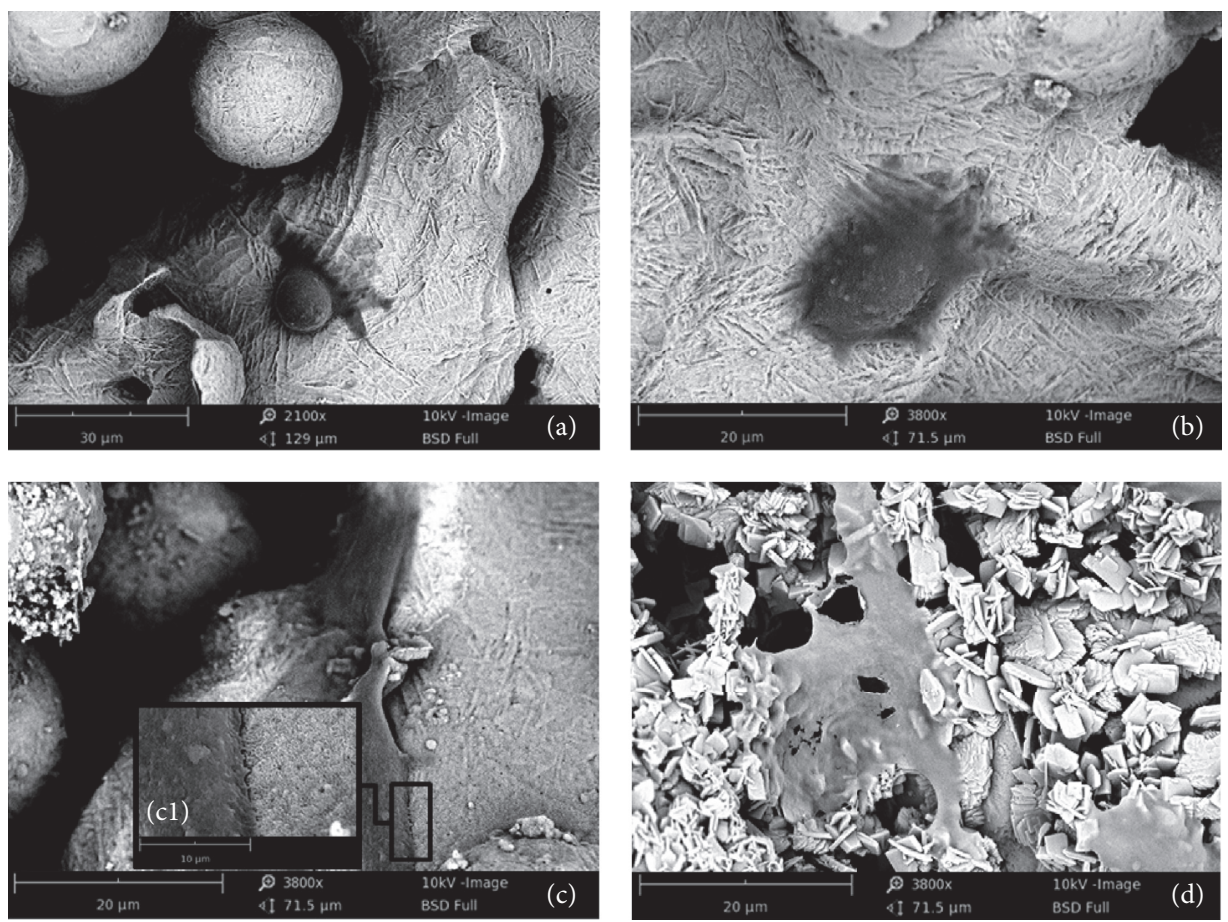

FIGURE 6: SEM micrographs of MG63 cells cultivated on the bare Ti surface (a) and on the CaP coatings at different electrolytic concentrations: group $10^{-4}(\mathrm{~b})$, group $10^{-3}(\mathrm{c})$, and group $10^{-2}(\mathrm{~d})$. The adherence between cell and porous surface was shown in high magnification $(\mathrm{cl})$. 
has better osteoinductive ability as its composition is similar to that of natural bone.

The superficial contact angle also determines the performance of this biomaterial coating. We studied the hydrophilicity of material surfaces and found that smaller contact angles favor hydrophilicity in materials and consequently increase the cellular affinity [41]. After implantation, the surface of the implants is covered with water molecules [42]. One side of the water molecule adheres to the implant surface while the other side is absorbed by hydrated ions, such as $\mathrm{Cl}^{-}, \mathrm{Na}^{+}$, and $\mathrm{Ca}^{2+}$. This is followed by adherence to osteogenesis-related proteins and osteoblasts. The adherence strength strongly depends on the surface properties of the implant [43]. The hydrophilicity of the materials is closely related to the number of $\mathrm{OH}^{-}$groups presented on the surface [44]. Meanwhile, the Ti-OH groups have a significant effect on the formation of apatite, which contributes to the deposition of $\mathrm{CaP}$ coating that bonds with the natural bone [45]. Accordingly, both plasma proteins and osteoblastic cells have stronger adhesion to hydrophilic surfaces in both in vitro and in vivo experiments. The great compatibility between hydration shell and water ensures that HAP has favorable hydrophilic properties [46]. Therefore, CaP coating improves the surface of a specimen by decreasing the contact angles, thus increasing the wettability and interface energy of the surface. Previous studies have reported that an increase in interface energy improves the active sites presented on the surface of titanium, thereby enhancing the cellular adhesion and extension [47].

In this research study, comparing a bare DLMF surface, MG63 cells spread and stretched better on the porous network structure of the $\mathrm{CaP}$ coated implants in group $10^{-3}$ and group $10^{-2}$. Accordingly, the porous structure of $\mathrm{CaP}$ coating enhances the surface area of $\mathrm{Ti}$ implant, offering more adhesive sites/motifs for the osteoblasts. The CaP ions released from the coatings provide a microenvironment with a higher affinity for culture of osteoblastic cells. Furthermore, the $\mathrm{CaP}$ coating provides adhesion sites for proteins and hydrophilic ions $\left(\mathrm{Cl}^{-}\right.$and $\left.\mathrm{Na}^{+}\right)$, thereby facilitating the adhesion and migration of cells at the surface and osteogenic activity of cultured cells at an early stage.

\section{Conclusion}

By using the electrochemical deposition, porous $\mathrm{CaP}$ coated DLMF implants were produced in three different concentrations of the electrolyte. XRD and FTIR analysis demonstrated the coating was predominantly constituted of HAP and wellordered in group $10^{-3}$. Moreover, the hydrophilic surface and cellular affinity were also significantly improved. By analyzing and evaluating the surface properties we have provided further knowledge on the electrolytic concentration effect, which is critical for improving $\mathrm{CaP}$ coatings on $\mathrm{Ti}$ implants in the future.

\section{Competing Interests}

The authors declare that there is no conflict of interests regarding the publication of this paper.

\section{Authors' Contributions}

Qianyue Sun and Yuhui Yang contributed equally to this study.

\section{Acknowledgments}

This work was supported in part by National Science Foundation of China (Grant nos. 81320108011, 81200809). The authors also appreciate Leader Italia for providing free TixOs plates and Engineering Laboratory of Changchun Institute of Applied Chemistry, Chinese Academy of Sciences for providing technical assistance.

\section{References}

[1] M. Geetha, A. K. Singh, R. Asokamani, and A. K. Gogia, "Ti based biomaterials, the ultimate choice for orthopaedic implants-a review," Progress in Materials Science, vol. 54, no. 3, pp. 397-425, 2009.

[2] T. Karachalios, C. Tsatsaronis, G. Efraimis et al., "The long-term clinical relevance of calcar atrophy caused by stress shielding in total hip arthroplasty: a 10-year, prospective, randomized study," The Journal of Arthroplasty, vol. 19, no. 4, pp. 469-475, 2004.

[3] T. Hanawa, "Biofunctionalization of titanium for dental implant," Japanese Dental Science Review, vol. 46, no. 2, pp. 93101, 2010.

[4] C. Mangano, F. G. Mangano, J. A. Shibli et al., "Immediate loading of mandibular overdentures supported by unsplinted direct laser metal-forming implants: results from a 1-year prospective study," Journal of Periodontology, vol. 83, no. 1, pp. 70-78, 2012.

[5] C. Mangano, F. Mangano, J. A. Shibli et al., "Prospective clinical evaluation of 201 direct laser metal forming implants: results from a 1-year multicenter study," Lasers in Medical Science, vol. 27, no. 1, pp. 181-189, 2012.

[6] J. A. Shibli, C. Mangano, S. D’Avila et al., "Influence of direct laser fabrication implant topography on type IV bone: a histomorphometric study in humans," Journal of Biomedical Materials Research Part A, vol. 93, no. 2, pp. 607-614, 2010.

[7] T. Traini, C. Mangano, R. L. Sammons, F. Mangano, A. Macchi, and A. Piattelli, "Direct laser metal sintering as a new approach to fabrication of an isoelastic functionally graded material for manufacture of porous titanium dental implants," Dental Materials, vol. 24, no. 11, pp. 1525-1533, 2008.

[8] S. R. Paital and N. B. Dahotre, "Calcium phosphate coatings for bio-implant applications: materials, performance factors, and methodologies," Materials Science and Engineering R: Reports, vol. 66, no. 1-3, pp. 1-70, 2009.

[9] A. R. Boccaccini, S. Keim, R. Ma, Y. Li, and I. Zhitomirsky, "Electrophoretic deposition of biomaterials," Journal of the Royal Society Interface, vol. 7, no. 5, pp. S581-S613, 2010.

[10] C.-J. Chung and H.-Y. Long, "Systematic strontium substitution in hydroxyapatite coatings on titanium via micro-arc treatment and their osteoblast/osteoclast responses," Acta Biomaterialia, vol. 7, no. 11, pp. 4081-4087, 2011.

[11] S. Shadanbaz and G. J. Dias, "Calcium phosphate coatings on magnesium alloys for biomedical applications: a review," Acta Biomaterialia, vol. 8, no. 1, pp. 20-30, 2012.

[12] A. M. Ballo, W. Xia, A. Palmquist et al., "Bone tissue reactions to biomimetic ion-substituted apatite surfaces on titanium 
implants," Journal of the Royal Society Interface, vol. 9, no. 72, pp. 1615-1624, 2012.

[13] L. T. de Jonge, S. C. G. Leeuwenburgh, J. G. C. Wolke, and J. A. Jansen, "Organic-inorganic surface modifications for titanium implant surfaces," Pharmaceutical Research, vol. 25, no. 10, pp. 2357-2369, 2008.

[14] P. He, S. Sahoo, K. S. Ng, K. Chen, S. L. Toh, and J. C. H. Goh, "Enhanced osteoinductivity and osteoconductivity through hydroxyapatite coating of silk-based tissue-engineered ligament scaffold," Journal of Biomedical Materials Research Part A, vol. 101, no. 2, pp. 555-566, 2013.

[15] R. H. M. ten Broeke, A. Alves, A. Baumann, J. J. C. Arts, and R. G. T. Geesink, "Bone reaction to a biomimetic thirdgeneration hydroxyapatite coating and new surface treatment for the Symax hip stem," The Journal of Bone \& Joint SurgeryBritish Volume, vol. 93, no. 6, pp. 760-768, 2011.

[16] M. Vallet-Regí, I. Izquierdo-Barba, and M. Colilla, "Structure and functionalization of mesoporous bioceramics for bone tissue regeneration and local drug delivery," Philosophical Transactions of the Royal Society A: Mathematical, Physical and Engineering Sciences, vol. 370, no. 1963, pp. 1400-1421, 2012.

[17] W. Suchanek and M. Yoshimura, "Processing and properties of hydroxyapatite-based biomaterials for use as hard tissue replacement implants," Journal of Materials Research, vol. 13, no. 1, pp. 94-117, 1998.

[18] M. F. Hasan, J. Wang, and C. Berndt, "Evaluation of the mechanical properties of plasma sprayed hydroxyapatite coatings," Applied Surface Science, vol. 303, pp. 155-162, 2014.

[19] Z. Ma, H. Ji, X. Hu et al., "Investigation of bioactivity and cell effects of nano-porous sol-gel derived bioactive glass film," Applied Surface Science, vol. 284, pp. 738-744, 2013.

[20] S. A. Pauline and N. Rajendran, "Biomimetic novel nanoporous niobium oxide coating for orthopaedic applications," Applied Surface Science, vol. 290, pp. 448-457, 2014.

[21] S. W. Park, D. Lee, H. R. Lee et al., "Generation of functionalized polymer nanolayer on implant surface via initiated chemical vapor deposition (iCVD)," Journal of Colloid and Interface Science, vol. 439, pp. 34-41, 2015.

[22] M. M. M. Bilek, "Biofunctionalization of surfaces by energetic ion implantation: review of progress on applications in implantable biomedical devices and antibody microarrays," Applied Surface Science, vol. 310, pp. 3-10, 2014.

[23] D.-Y. Lin and X.-X. Wang, "Preparation of hydroxyapatite coating on smooth implant surface by electrodeposition," Ceramics International, vol. 37, no. 1, pp. 403-406, 2011.

[24] J. A. Jansen and B. Leon, Thin Calcium Phosphate Coatings for Medical Implants, Springer, 2009.

[25] F. Barrere, C. A. Van Blitterswijk, K. De Groot, and P. Layrolle, "Influence of ionic strength and carbonate on the Ca-P coating formation from SBF $\times 5$ solution," Biomaterials, vol. 23, no. 9, pp. 1921-1930, 2002.

[26] M. A. Lopez-Heredia, P. Weiss, and P. Layrolle, "An electrodeposition method of calcium phosphate coatings on titanium alloy," Journal of Materials Science: Materials in Medicine, vol. 18, no. 2, pp. 381-390, 2007.

[27] J. Hernandez-Montelongo, D. Gallach, N. Naveas et al., "Calcium phosphate/porous silicon biocomposites prepared by cyclic deposition methods: spin coating vs electrochemical activation," Materials Science and Engineering C, vol. 34, no. 1, pp. 245-251, 2014.
[28] D. Olton, J. Li, M. E. Wilson et al., "Nanostructured calcium phosphates (NanoCaPs) for non-viral gene delivery: influence of the synthesis parameters on transfection efficiency," Biomaterials, vol. 28, no. 6, pp. 1267-1279, 2007.

[29] M. C. Kuo and S. K. Yen, "The process of electrochemical deposited hydroxyapatite coatings on biomedical titanium at room temperature," Materials Science and Engineering C, vol. 20, no. 1-2, pp. 153-160, 2002.

[30] B. E. Prasad and P. V. Kamath, "Electrodeposition of dicalcium phosphate dihydrate coatings on stainless steel substrates," Bulletin of Materials Science, vol. 36, no. 3, pp. 475-481, 2013.

[31] J. M. Zhang, C. J. Lin, Z. D. Feng, and Z. W. Tian, "Mechanistic studies of electrodeposition for bioceramic coatings of calcium phosphates by an in situ $\mathrm{pH}$-microsensor technique," Journal of Electroanalytical Chemistry, vol. 452, no. 2, pp. 235-240, 1998.

[32] Y. Yoshida, K. Inoue, N. Kyritsakas, and M. Kurmoo, "Syntheses, structures and magnetic properties of zig-zag chains of transition metals with O-P-O bridges," Inorganica Chimica Acta, vol. 362, no. 5, pp. 1428-1434, 2009.

[33] M. Kumar, J. Xie, K. Chittur, and C. Riley, “Transformation of modified brushite to hydroxyapatite in aqueous solution: effects of potassium substitution," Biomaterials, vol. 20, no. 15, pp. 1389-1399, 1999.

[34] M. Kumar, H. Dasarathy, and C. Riley, "Electrodeposition of brushite coatings and their transformation to hydroxyapatite in aqueous solutions," Journal of Biomedical Materials Research, vol. 45, no. 4, pp. 302-310, 1999.

[35] H. K. Varma and S. S. Babu, "Synthesis of calcium phosphate bioceramics by citrate gel pyrolysis method," Ceramics International, vol. 31, no. 1, pp. 109-114, 2005.

[36] F. Miyaji, Y. Kono, and Y. Suyama, "Formation and structure of zinc-substituted calcium hydroxyapatite," Materials Research Bulletin, vol. 40, no. 2, pp. 209-220, 2005.

[37] A. R. Boyd, B. J. Meenan, and N. S. Leyland, "Surface characterisation of the evolving nature of radio frequency $(\mathrm{RF})$ magnetron sputter deposited calcium phosphate thin films after exposure to physiological solution," Surface and Coatings Technology, vol. 200, no. 20-21, pp. 6002-6013, 2006.

[38] T. Kokubo, "Formation of biologically active bone-like apatite on metals and polymers by a biomimetic process," Thermochimica Acta, vol. 280-281, pp. 479-490, 1996.

[39] F. J. García-Sanz, M. B. Mayor, J. L. Arias, J. Pou, B. León, and M. Pérez-Amor, "Hydroxyapatite coatings: a comparative study between plasma-spray and pulsed laser deposition techniques," Journal of Materials Science: Materials in Medicine, vol. 8, no. 12, pp. 861-865, 1997.

[40] P. Noisong, C. Danvirutai, T. Srithanratana, and B. Boonchom, "Synthesis, characterization and non-isothermal decomposition kinetics of manganese hypophosphite monohydrate," Solid State Sciences, vol. 10, no. 11, pp. 1598-1604, 2008.

[41] C.-Y. Hsieh, S.-P. Tsai, M.-H. Ho et al., "Analysis of freezegelation and cross-linking processes for preparing porous chitosan scaffolds," Carbohydrate Polymers, vol. 67, no. 1, pp. 124132, 2007.

[42] J. Talbot, G. Tarjus, P. R. Van Tassel, and P. Viot, "From car parking to protein adsorption: an overview of sequential adsorption processes," Colloids and Surfaces A: Physicochemical and Engineering Aspects, vol. 165, no. 1-3, pp. 287-324, 2000.

[43] T. Albrektsson, R. Jimbo, and A. Wennerberg, "Overview of surface microtopography/chemistry/physics/nano-roughness," in Implant Surfaces and Their Biological and Clinical Impact, pp. 7-12, Springer, Berlin, Germany, 2015. 
[44] E. Milella, F. Cosentino, A. Licciulli, and C. Massaro, "Preparation and characterisation of titania/hydroxyapatite composite coatings obtained by sol-gel process," Biomaterials, vol. 22, no. 11, pp. 1425-1431, 2001.

[45] Y. Chen, X. Zheng, H. Ji, and C. Ding, "Effect of Ti-OH formation on bioactivity of vacuum plasma sprayed titanium coating after chemical treatment," Surface and Coatings Technology, vol. 202, no. 3, pp. 494-498, 2007.

[46] J. Y. Martin, Z. Schwartz, T. W. Hummert et al., "Effect of titanium surface roughness on proliferation, differentiation, and protein synthesis of human osteoblast-like cells (MG63)," Journal of Biomedical Materials Research, vol. 29, no. 3, pp. 389401, 1995.

[47] N. J. Hallab, K. J. Bundy, K. O’Connor, R. L. Moses, and J. J. Jacobs, "Evaluation of metallic and polymeric biomaterial surface energy and surface roughness characteristics for directed cell adhesion," Tissue Engineering, vol. 7, no. 1, pp. 55-71, 2001. 

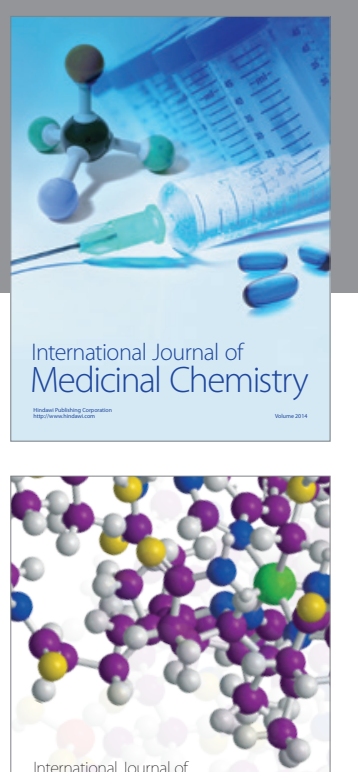

Carbohydrate Chemistry

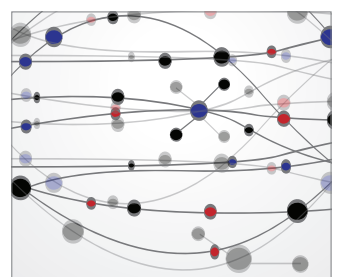

The Scientific World Journal
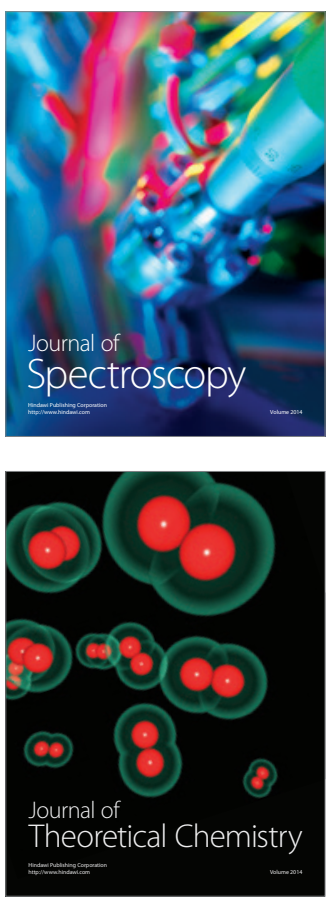
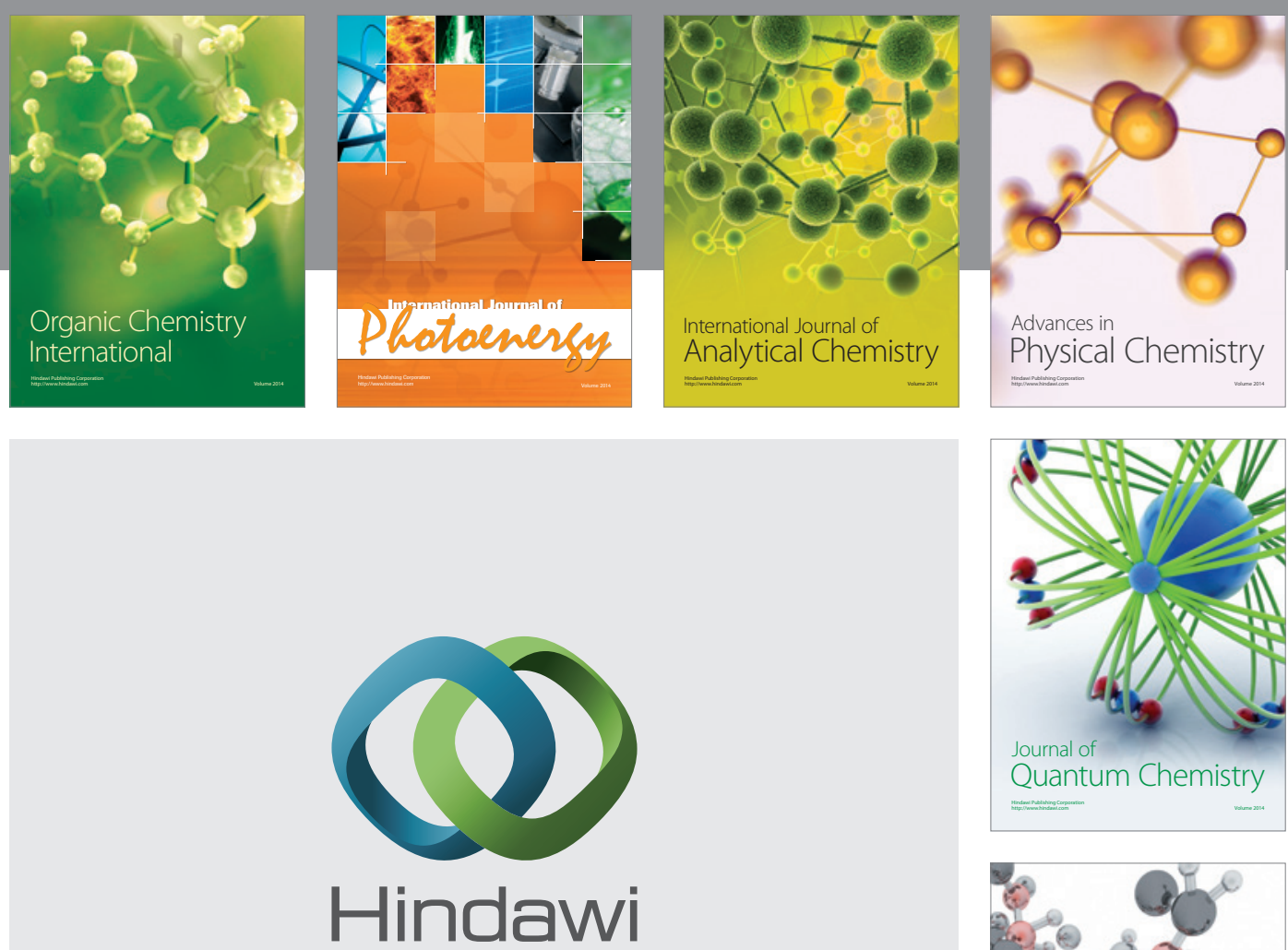

Submit your manuscripts at

https://www.hindawi.com

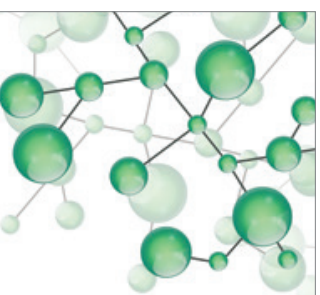

International Journal of

Inorganic Chemistry
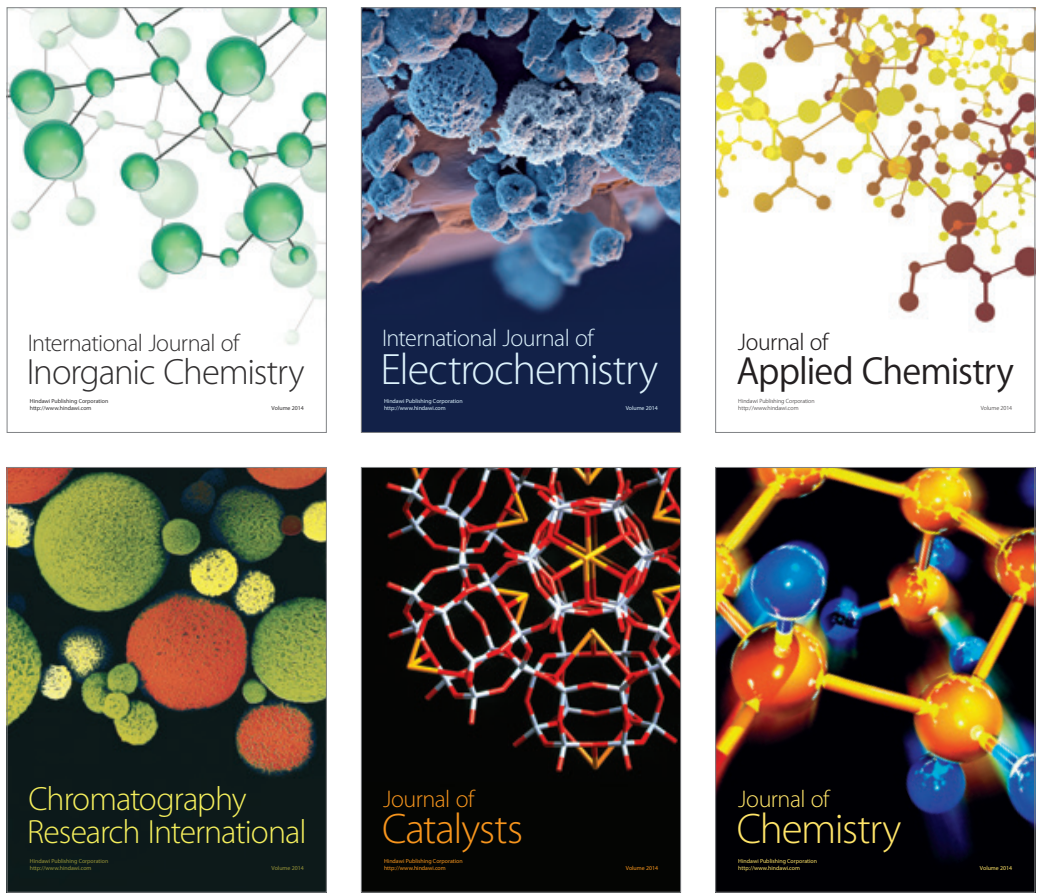

Journal of

Applied Chemistry
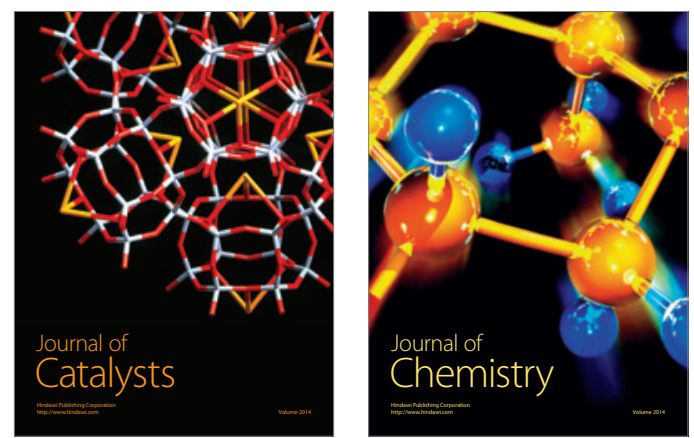
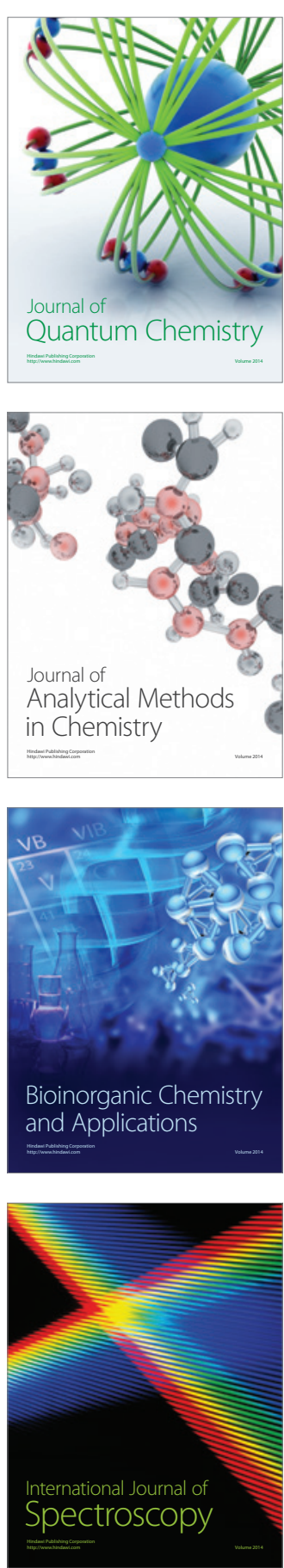